\title{
MESOSSAURÍDEO (STEREOSTERNUM TUMIDUM) E CRUSTÁCEO (LIOCARIS HUENEI) NO MEMBRO ASSISTÊNCIA DA FORMAÇÃO IRATI (P) NOS MUNICÍPIOS DE JATAÍ E MONTEVIDIU, ESTADO DE GOIÁS
}

\author{
PERCY C. VIEIRA*, SÉRGIO MEZZALIRA**, FRANCISCO J.F. FERREIRA***
}

\begin{abstract}
MESOSAURID (STEREOSTERNUM TUMIDUM) AND CRUSTACEA (LIOCARIS HUENEI) IN THE ASSISTENCIA MEMBER OF THE IRATI FORMATION (PERMIAN) AT JATAI AND MONTEVIDIU GOIA S. The results of studies of vertebrate and crustracea remains from quarries for dolomite sou buffer at Perolândia (Jataí Municipality) and Boa Vista (Montevidiu Municipality), State of Goiás, Brazil, are presented in this paper. These dolomites are here correlated to the Assistência Member of the Permian Irati Formation of the State of São Paulo. The fossils were identified as Stereosternum tumidum Cope 1886 (Reptilia) and Liocaris huenei Beurlen 1931 (Crustacea). fchnofossik and organic animal remains were not classified. The Guapiara Alignment, according to the proposition here presented, might be a barrier during the Irati deposition so the Assistência Member with the reptils Stereosternum and Brazilosaurus was restricted to the north of this alignment South of this alignment the Irati sediments were mainly shales bearing the réptil Mesosaurus brasiliensis.
\end{abstract}

Keywords: Stereosternum tumidum, Liocaris Huenei, Irati Formation, Assistência Member, Guapiara Alignment

\begin{abstract}
RESUMO Este trabalho divulga o resultado dos estudos fossilíferos realizados nas pedreiras de Perolândia (Município de Jataí) e Boa Vista (Município de Montevidiu) no Estado de Goiás, destinadas à extracão de dolomite para corretivo de acidez de solos, e aqui correlacionadas ao Membro Assistência da Formacão Irati do Estado de São Paulo. Os fósseis encontrados são o mesossaurídeo Stereosternum tumidum Cope 1886, o crustáceo Liocaris huenei Beurlen 1931, icnofósseis indeterminados e restos orgânicos de animais, também indeterminados. E proposto que o Alinhamento de Guapiara constituiu-se em uma barreira durante a deposição da Formação Irati, formando-se, ao norte, o Membro Assistência com Stereosternum e Brazilosaurus e, ao sul, predominantemente pelitos com Mesosaurus brasiliensis.
\end{abstract}

Palavras-chaves: Stereosternum tumidum, Liocaris Huenei, Formação Irati, Membro Assistência, Alinhamento Guapiara.

INTRODUÇ̃̃O Deve-se a Teixeira (1932) a citação da existência de ossos de mesossaurídeos em sedimentos da Formação Irati na região de Montevidiu e Jataí, sudoeste de Goiás (Fig. 1). Outros autores posteriormente fizeram referências ao assunto, com especial destaque a Milward (1935), que teria precedido Teixeira (1932) na descoberta. Contudo, somente Vasconcelos (1973) referiu-se especificamente aos mesossaurídeos como Mesosaurus brasiliensis nesses sedimentos do Município de Jataí. Rosier (1985), analisando uma amostra procedente desse município, sugeriu que se tratava de Brasilosaurus sampauloensis e que o animal seria vivíparo. Sedor \& Rösler (1985), referindo-se à mesma amostra de Rosier (1985) aventaram a possibilidade de relações entre indivíduos jovens e um adulto. Mezzalira et al (1990) consideraram a unidade litoestratigráfica como semelhante ao Membro Assistência do Estado de São Paulo e propuseram que o réptil seria provavelmente Stereosternum tumidum. Nesse mesmo trabalho, divulgaram o encontro inédito de Crustacea-Malacostraca referida ao gênero Liocaris Beurlen.

Visita a Jataí e Montevidiu em 1986 levou os autores deste artigo à coleta e estudos do material, cujos resultados são aqui divulgados.

OBJETIVOS São objetivos deste trabalho situar litoestratigraficamente a unidade em estudo (Membro Assistência), identificar os fósseis encontrados, discutir o ambiente de deposição dos sedimentos, bem como tentar ajustá-lo ao contexto geotectônico predominante durante a sedimentação da unidade.
MATERIAL E MÉTODOS Foram visitadas as pedreiras de extração de dolomito para corretivo de acidez de solos, do Distrito de Perolândia (Município de Jataí) e do Município de Montevidiu, das quais foram coletadas várias amostras; outras amostras foram obtidas por doação e, delas todas, as melhores foram cadastradas na coleção da Seção de Paleontologia e Estratigrafia do Instituto Geológico.

O material foi estudado petrológica e paleontologicamente por meio de lâminas delgadas, análises químicas e por difiratogramas de raios $\mathrm{X}$.

CONSIDERAÇÕES GEOLÓGICAS As pedreiras estudadas constituem-se de dolomites do Membro Assistência da Formação Irati de Barbosa \& Gomes (1958), proposta para o Estado de São Paulo. Compõem-se de lentes e bancos claros (branco-amarelados) de carbonates micrito-esparíticos com poucos grãos de quartzo, algo siliciticados, contendo lâminas argilosas de cor cinza e folhelhos pretos pirobetuminosos. A espessura dos bancos varia de centímetros a poucos metros, podendo alcançar até $10 \mathrm{~m}$. Os folhelhos mostraramse macroscopicamente afossilíferos, ficando os fósseis restritos aos carbonato.

Conforme difratogramas por raios X obtidos pela Divisão de Geologia e Recursos Minerais do Instituto de Pesquisas Tecnológicas (DGRM - IPT), a rocha carbonática constitui-se de dolomita (essencial) e quartzo (quantidade menor), formando as camadas claras mais espessas, enquanto as lâminas escuras compõem-se do argilomineral do grupo da esmectita. Trata-se, portanto, de ritmito formado por dolomito contendo grãos de quartzo, alternado com argilito.

\footnotetext{
* Instituto Geológiço, Secretaria do Meio Ambiente do Estado de São Paulo, Avenida Miguel Stéfano, 3900, Á gua Funda, CEP 04301, São Paulo, SP, Brasil ** Rua Nanau, 77, A gua Fria, CEP 02335, São Pauto, SP, Brasil

*** Departamento de Geologia, Universidade Bederal do Paraná, Caixa Postal 19011, CEP 81531, Curitiba, PR, Brasil
} 


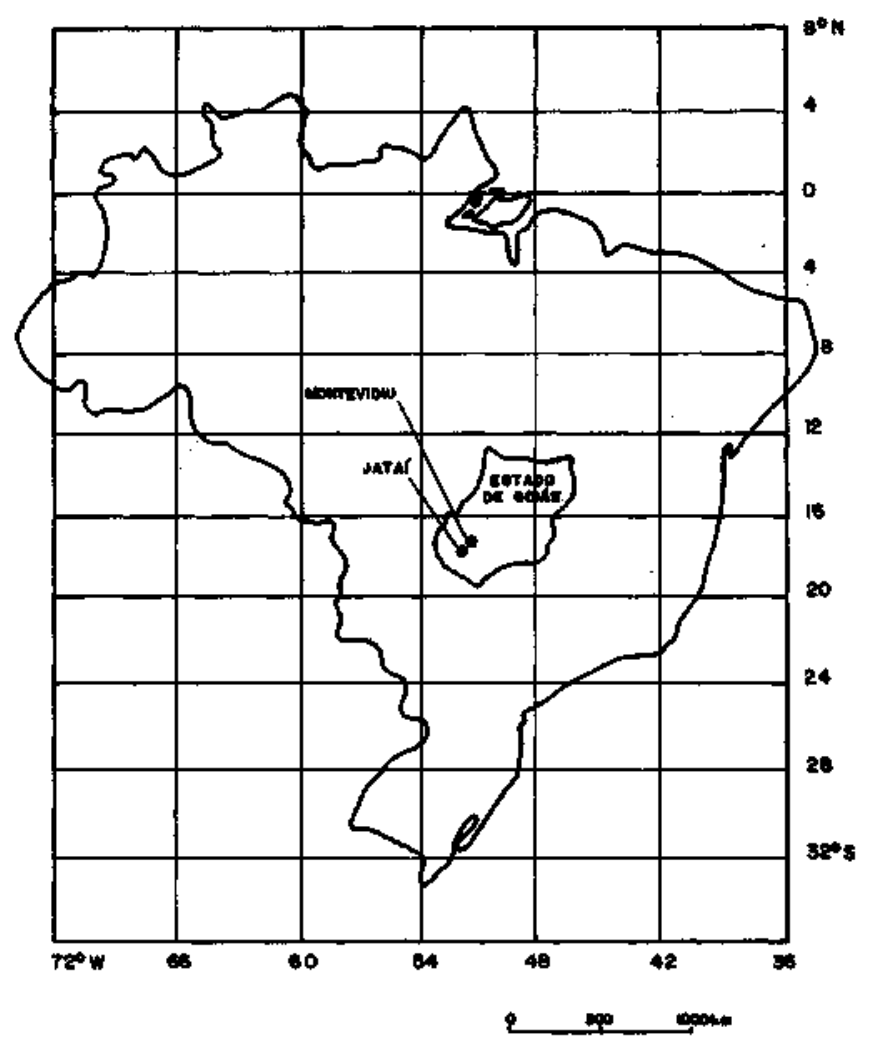

Figura 1 - Localização da região estudada Figure 1 - Localization of the studied legion

Nos municípios de Jataí e Montevidiu ocorrem as Formações Botucatu e Serra Geral, o Grupo Bauru e a Formação Cachoeirinha (Terciário). Em Jataí, a Formacão Irati aflora por elevação em blocos de falhas normais (DNPM 1975). Num barranco próximo à pedreira de Perolândia ocorre 0 Membro Serra Alta da Formação Estrada Nova. Na mesma pedreira há uma intrusão básica. Em Montevidiu, a Formação Irati aflora no vale do Rio Piratinga.

A amostra da foto 2 da prancha 1 constitui-se de dolomito claro com leitos de espessuras de 0,3 a $0,5 \mathrm{~cm}$, contendo lentes de sílex de poucos centímetros de extensão por $0,2 \mathrm{~cm}$ de espessura, alternados com finas lâminas esmectíticas escuras. Uma lâmina exibe marcas onduladas com comprimento de onda de, no máximo, $0,5 \mathrm{~cm}$ por, no mínimo, $0,1 \mathrm{~cm}$ de amplitude.

A amostra da foto 3 da prancha 1 constitui-se de dolomito com leitos de espessuras de milímetros a $1 \mathrm{~cm}$, alternados com finas lâminas esmectíticas escuras, com gretas de contração, uma das quais com espessura de $1,5 \mathrm{~cm}$. As profundidades das gretas são de milímetros a $1 \mathrm{~cm}$. O preenchimento é feito por material carbonático. O aspecto é anastomosado, com algumas gretas curvas aproximadamente concêntricas, ligadas a outras radiais. Petri \& Coimbra (1982) já citaram a existência de gretas de contração curvas no Irati do Estado de São Paulo.

As gretas circundam um esqueleto de réptil, o qual sugere que a sua presença originou uma área de fraqueza de onde partiram as rachaduras. As gretas são formadas pela cristalização salina em exposição aérea, dando origem a pequenos domos que seriam responsáveis pela formação de rachaduras curvas ao redor de áreas centrais.

No quadro 1, as espessuras das litologias no Estado de Goiás foram anotadas a grosso modo quando da visita às pedreiras de Perolândia e Boa Vista. A espessura total da
Formação Irati na região sudoeste do Estado de Goiás é de $41 \mathrm{~m}$, conforme sondagem realizada pela Petrobrás nos arredores de Jataí, sendo a mesma atingida na profundidade entre 303 e 344 m (Amaral 1971).

Mezzalira (1971) mencionou que "é comum ocorrerem na Formação Irati intrusões de rochas basálticas, e estas têm-se verificado, principalmente, na unidade superior, sendo raro e mesmo desconhecido... na Litofácies B". Na pedreira de Perolândia, foi observada uma intrusão básica que causou dobramento nas rochas do Membro Assistência.

ESTUDO E DESCRIÇÃO DOS FÓSSEIS Icnofósseis A foto 1 da prancha 1 mostra dolomito claro, acamado, com cada leito apresentando $0,8 \mathrm{~cm}$ de possança, separado do seguinte por fina lâmina escura esmectítica. Numa das lâminas há uma pista retilínea com aproximadamente 0,8 $\mathrm{cm}$ de largura, com dois sulcos laterais e pequeno sulco no meio, dividindo um lado côncavo de outro convexo. Há uma ramificação mais estreita com o mesmo aspecto. A mesma lâmina mostra outra pista retilínea, com aproximadamente 0,8 $\mathrm{cm}$ de largura, com dois sulcos laterais, e convexa no centro. Há uma ramificação curva com $0,5 \mathrm{~cm}$ de largura. Etnologicamente, podem ser classificadas como Pascicnia, segundo Seilacher (apud Suguio 1980), topologicamente como Epicnia, segundo Martinsson (apud Suguio 1980).

$\mathrm{Na}$ amostra da foto 2 (Prancha 1), descrita no item anterior, as marcas onduladas estão superimpostas por uma pista retilínea ligeiramente curva, com cerca de $0,6 \mathrm{~cm}$ de largura, mostrando ramificação com $0,3 \mathrm{~cm}$ de largura. A direção das pistas é aproximadamente paralela à do sentido da corrente aquosa. Podem ser classificadas etnologicamente como Pascicnia, segundo Seilacher (apud Suguio 1980) e topologicamente como Epicnía ou Hipicnia, segundo Martinsson (apud Suguio 1980); a dúvida é devida ao fato de que a amostra foi apanhada fora da posição original.

Proganosauría - Mesosauridae STEREOSTERNUM TUMIDUM COPE 1886 Conforme difratogramas de raios X obtidos pela DGRM - IPT, os contramoldes dos esqueletos constituem-se de apatita (possivelmente carbonato-apatita). O contramolde do esqueleto da amostra da foto 1 da Prancha 3 contém também um argilomineral associado, provavelmente caulinita. A análise química efetuada pelo Instituto de Geociéncias da Universidade de São Paulo (IGIUSP) no contramolde do réptil constatou as quantidades de 49,98\% de $\mathrm{CaO}$ e $34,44 \%$ de $\mathrm{P}_{2} \mathrm{O}_{5}$, mais $\mathrm{CO}_{3}^{-2}$, e a presença qualitativa de $\mathrm{Fe}^{+3}$, assim como de resíduo insolúvel, provavelmente de $\mathrm{SiO}_{2}$ (não foi feita análise para magnésio).

Em seções delgadas, o material ósseo mostra ser microcristalino esparitico, composto por mineral anisotrópico. Isso faz concluir que o processo de fossilização deu-se por substituição, com neof armação do mineral carbonato-apatita, para o qual contribuíram a rocha matriz e os esqueletos.

Crânio e dentição O tamanho do crânio varia de $2,8 \mathrm{~cm}$ no indivíduo jovem da foto 5 da prancha 2 , a $6,2 \mathrm{~cm}$ no da foto 3 da prancha 1 (valor este duvidoso pelo fato de o crânio não estar bem fossilizado), passando pelo valor de $5,0 \mathrm{~cm}$ num dos indivíduos da foto 1 da prancha 2.

O crânio do espécime da foto 5 da prancha 2 tem a parte posterior superior não-conservada, mostrando deslocamento para cima e compressão com a coluna cervical na sua parte inferior, maxila reta e grande dimensão da cavidade orbital.

Como características específicas, tem-se que a forma do crânio é triangular, alongada no adulto, com proporção comprimento/largura máxima de um para 0,18 . A relaçăo de seu comprimento com o do pescoço não pode ser obtida, com exceção do espécime jovem da foto 5 da prancha 2 , o que não serve para caracterização específica, como será visto no subitem Tamanho e Juventude. 


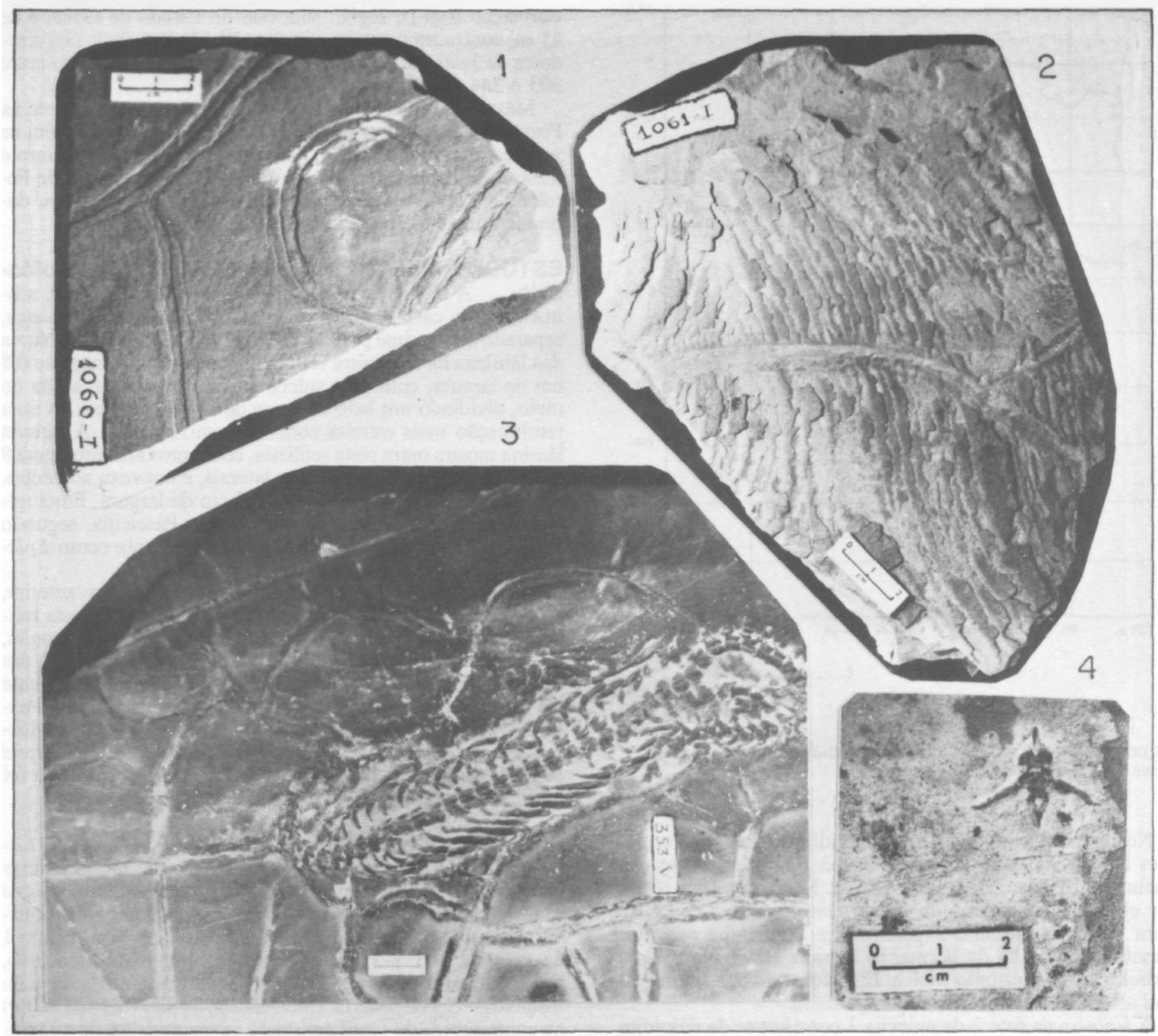

Prancha 1 - 1. Pista (Pascicnia/Epicnia). Pedreira Boa Vista (Município de Montevidiu); 2. Marcas onduladas e pista (Pascicnia/Epicnia cai Hipicnia). Distrito de Perolândia (Município de Jataí); 3. Gretas de contração circundando esqueleto de Stereosternum tumidum. Distrito de Perolândia (Município de Jataí); 4. Vista posterior de vertebra caudal de Stereosternum tumidum. Pedreira Boa Vista (Município de Montevidiu)

Plate 1-1. Trail (Pascicnia/Epicnia). Boa Vista Quarry (Montevidiu Municipality); 2. Ripple marks and trail (Pascicnia/Epicnia or Hipicnia). Perolândia District (Jataí Municipality); 3. Mud cracks around Stereosternum tumidum skeleton. Perolândia District (Jataí Municipality); 4. Hind view of trail vertebra of Stereosternum tumidum. J3oa Vista Quarry (Montevidiu Municipality)

Em vista lateral direita (Foto 5 - Prancha 2), podem ser vistos os seguintes ossos: jugal, escamoso, tabular, pós-orbital, pré-frontal, frontal, lacrimal, nasal, pré-maxilar, maxilar, septomaxilar, angular, suprangular e dental. Entre o escamoso e o tabular aparece uma lacuna óssea que talvez seja correspondente à fenestra temporal encontrada por Huene (1941) em Mesosaurus brasiliensis. Na porção anterior do lacrimal, aparece uma estrutura que se assemelha ao foramem narial obturado descrito por Huene (1941).

Em vista superior (Foto 1 - Prancha 3), o assoalho da caixa craniana (pálato) mostra os seguintes ossos: paraesfende, basioccipital, pré-articular, quadrato e fragmentos não identificáveis.

O exemplar da foto 5 da prancha 2 mostra o anel esclerótico composto por placas ósseas (partes hachuradas da Fig. 2) e por moldes de placas ósseas (partes não-hachuradas). A única citação até então existente de anel esclerótico em mesossaurídeos é encontrada em Borgomanero \& Leonardi (1979).

Quanto a dentição, a espécie possui implantação alveolar, com dentes retos, cônicos e pouco alongados. O exemplar da foto 1 da prancha 2 possui três dentes conservando o esmalte, apresentando estriação longitudinal, com saliências e reentrâncias, conforme mostra a figura 3. Eles são cônicos, sendo que o mais conservado tem dimensões de $0,22 \mathrm{~cm}$ de comprimento por $0,08 \mathrm{~cm}$ de largura máxima; estão na mandíbula. No exemplar da foto 5 da prancha 2, os dentes da mandíbula são menores e mais numerosos do que os da maxila, alongados (embora cônicos), tendo sido feita contagem de 75; o mais longo mede $0,14 \mathrm{~cm}$ de comprimento por $0,04 \mathrm{~cm}$ de largura máxima. Na maxila, os dentes são maiores e menos numero- 
Quadro 1 - Correlação entre a Formação Irati dos Estados de Goịás (região sudoeste) e São Paulo Chart 1 - Correlation between the Irati Formation of (he States of Goiás (SW region) and Sã o Paulo

\begin{tabular}{|c|c|c|c|c|c|c|c|}
\hline & \multicolumn{4}{|c|}{ ESTADO DE SAO PAULO } & \multicolumn{3}{|c|}{ ESTADO DE GOIRs (Rer Lôn sudoeste) } \\
\hline & & Litologia & Fóstis & Espessura (m) & Linotogia & Foseis & Espessang (m) \\
\hline \multirow{3}{*}{$\begin{array}{l}\text { Litobioficies } \\
\text { A ou superior }\end{array}$} & $\begin{array}{l}\text { Ficies argilo-carbo- } \\
\text { ńtica (- Membro } \\
\text { Assisténcia BAR- } \\
\text { BOSA \& GOMES) }\end{array}$ & $\begin{array}{l}\text { Folhehos pirobetr- } \\
\text { minosos, fohelhos } \\
\text { pretos, dolcmitos } \\
\text { altemados com fo- } \\
\text { helhos, calctirios } \\
\text { inpros, silex }\end{array}$ & $\begin{array}{l}\text { Paulocarls } \\
\text { Pygabpts } \\
\text { Amaralia sp. } \\
\text { Sioneostemum } \\
\text { Espoces do } \\
\text { gymnospermas } \\
\text { Espicules d } \\
\text { esponjas }\end{array}$ & $10 \cdot 20$ & $\begin{array}{l}\text { Folhelhos pirobetu- } \\
\text { minceos, follhethos } \\
\text { pretos, dolomitos } \\
\text { altemidos com fo- } \\
\text { Ihellos, calcérios } \\
\text { com grsos de } \\
\text { quentro, silex }\end{array}$ & $\begin{array}{l}\text { Shereosternum } \\
\text { Ienofossei }\end{array}$ & 5 a 15 \\
\hline & $\begin{array}{l}\text { Fdcies siltico-argi- } \\
\text { losa (- Ficies Ri- } \\
\text { beirio Grande de } \\
\text { MENDES el aL) }\end{array}$ & Siltitos cinzentos & Restos de peixes & $0,5=3$ & & & $\therefore$ \\
\hline & 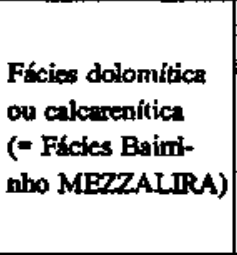 & $\begin{array}{l}\text { Dolomilos creme } \\
\text { esbratuquicados } \\
\text { e cinzentos }\end{array}$ & $\begin{array}{l}\text { Liocaris ap. } \\
\text { Madeirs fosets } \\
\text { Sueneasiemum } \\
\text { Espleules de } \\
\text { esponjas } \\
\text { Epponos de } \\
\text { gymospermss. }\end{array}$ & $2 \cdot 4,5$ & $\begin{array}{l}\text { Dolomitos branco- } \\
\text { mareledos, cin- } \\
\text { zemtos nus liminas } \\
\text { esmectldicas }\end{array}$ & $\begin{array}{c}\text { Llocaris } \\
\text { Stereosternum }\end{array}$ & 4 a 10 \\
\hline $\begin{array}{l}\text { Litobiof ccies } \\
\text { B ou inferior }\end{array}$ & $\begin{array}{l}\text { Ficles sflico-at- } \\
\text { gilo-arenof: } \\
\text { (- Membro Taqua } \\
\text { ra ALMEIDA } \\
\text { BARBOSA) }\end{array}$ & $\begin{array}{l}\text { Silttos clnzentos, } \\
\text { ambarelados } \\
\text { Arenitos } \\
\text { Arenito conglo- } \\
\text { mextico }\end{array}$ & $\begin{array}{l}\text { Clarkecarls } \\
\text { Restos de peixes } \\
\text { Espiculas de es- } \\
\text { ponjas (Leaindi- } \\
\text { dae-Pr Maackia } \\
\text { Pi) }\end{array}$ & $4 \cong 12$ & & & \\
\hline
\end{tabular}

Obs.: Neste trabalho a Fácies Bairrinho é entendida como pertencente ao Membro Assistência sensu latu, no Estado de Goiás.

Formação Irati no Estado de São Paulo extraída de Mezzalira (1971)

sos, alongados (embora mais cênicos do que os da mandíbula), tendo sido feita contagem de 37 (parte da maxila está encoberta); o maior mede $0,2 \mathrm{~cm}$ de comprimento por 0,08 de largura máxima. Nos dois dentes maiores, vê-se a cavidade antes ocupada pela dentina.

Região cervical A espécie apresenta doze vértebras cervicais, sendo que o atlas é mais longo do que o áxis que, por sua vez, é mais curto do que as outras vértebras. Do áxis para trás, as vértebras alargam-se, possuindo pequenas costelas cervicais que aumentam de tamanho para a região posterior. Com. exceção do atlas, do áxis (este bastante curto) e da terceira vertebra, as vértebras cervicais mostram centrum alongado. As espinhas neurais não são proeminentes e estão bem voltadas para trás.

$\mathrm{O}$ indivíduo da foto 1 da prancha 3 apresenta o centrum da terceira vertebra com $0,45 \mathrm{~cm}$ de comprimento por igual largura, em vista dorsal.

O pescoço do espécime da foto 5 da prancha 2 apresenta rotação de quase 90 graus no sentido anti-horário em relação ao tórax, o qual está em posição dorsal.

O canal medular do espécime da foto 1 da prancha 3 está preservado e parcialmente preenchido por material secundário, o que ocorre também com espécimes não fotografados.

O pescoço do espécime da foto 5 da prancha 2 tem comprimento de $4,3 \mathrm{~cm}$, enquanto o da foto 1 da prancha 3 tem comprimento de $6,7 \mathrm{~cm}$.

Região tóraco-lombar A espécie apresenta vinte e duas vértebras tóraco-lombares, com centrum quadrático em vista dorsal e apófises laterais (diapófises) voltadas para trás. As espinhas neurais são proeminentes, porém curtas e estão dispostas ântero-posteriormente nas vértebras posteriores.

As vértebras de posição mediana na coluna do indivíduo da foto 1 da prancha 3 mediram comprimento de $0,8 \mathrm{~cm}$ por largura de 0,9 cm. As vértebras lombares são mais finas e curtas.

As margens anterior e posterior são onduladas e mais largas do que longas, como observado por Shikama (1970). Há pequenas estriações e pequenos poros na face dorsal do centrum, sendo que as estrias alongam-se ântero-posteriormente, de acordo com verificações de Shikama (1970).

O canal medular do indivíduo da foto 1 da prancha 3 está preservado e parcialmente preenchido por material secundário, o que ocorre também com outros indivíduos estudados.

O comprimento entre as cinturas escápular e pélvica é de $13,5 \mathrm{~cm}$ no espécime da foto 1 da prancha 2 , que permite tal medição, e de $16 \mathrm{~cm}$ no da foto 1 da prancha 3 .

As costelas não estão coossificadas com as diapófises das vértebras; são robustas, mostrando o fim proximal (capítulo) recurvado, separado do tubérculo por pequena faceta. $\mathrm{O}$ capítulo é mais fino do que o tubérculo. A porção distai não é recurvada. A espessura máxima das costelas na foto $1 \mathrm{da}$ prancha 3 é de $0,2 \mathrm{~cm}$.

As costelas, em corte longitudinal, apresentam estriação ao longo de seu comprimento, além de um sulco mediano; em superfície, algumas mostram estrias longitudinais.

$\mathrm{O}$ exemplar da foto 1 da prancha 3 contém o plástron de costelas dérmicas abdominais estendendo-se da cintura escapular à pélvica, com costelas finas arranjadas em séries látero-longitudinais. São cerca de cinco vezes mais numerosas do que as costelas tóraco-lombares. Uma película sem textura, de cor amarelo-marrom parece ser secundária, mas de origem dérmica. $\mathrm{O}$ exemplar da foto 5 da prancha 2 contém também parcialmente costelas dérmicas abdominais.

Região caudal O número total de vértebras caudais é desconhecido, já que o material apresentado na foto 1 da prancha 3 mostra apenas dez vértebras e a cauda de um dos exemplares da foto 1 da prancha 2 não apresenta condições 


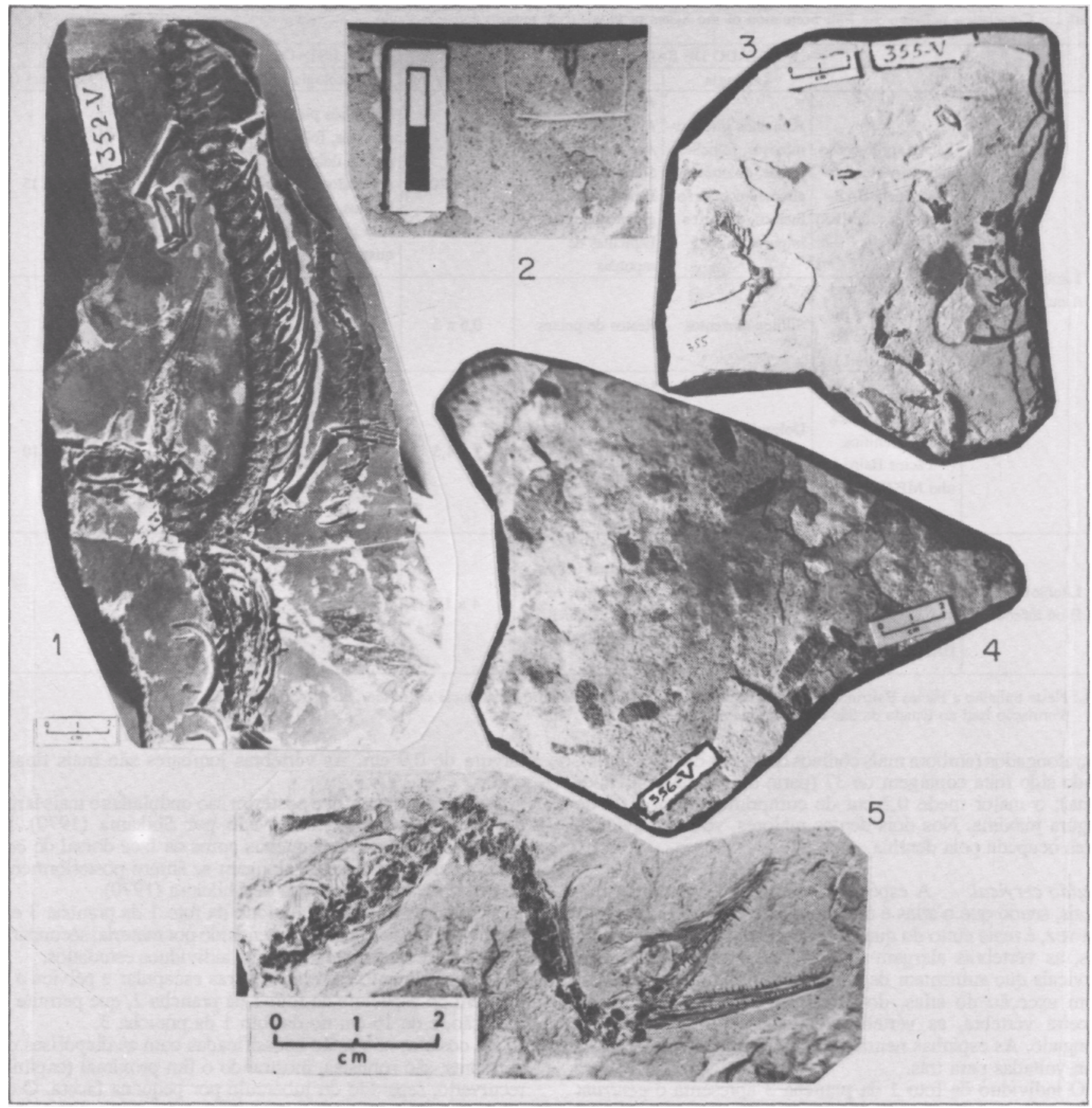

Prancha 2-1. Dois espécimes incompletos de Stereosternum tumidum. Pedreira Boa Vista (Município de Montevidiu); 2. Arco hemal isolado de Stereosternum tumidum (a escala tem comprimento de dois centímetros). Pedreira Boa Vista (Município de Montevidiu); 3. Restos de Stereosternum tumidum, destacando-se arcos hemais isolados. Distrito de Perolândia (Município de Jataí); 4. Nódulos com fragmentos ósseos de Stereosternum tumidum. Pedreira Boa Vista (Municipio de Montevidiu); 5. Indivíduo jovem (Stereosternum tumidum) apresentando rotação cervical e deslocamento do crânio. Distrito de Perolândia (Municipio de Jataí)

Plate 2-1. Two incomplete specimens of Stereosternum tumidum. Boa Vista Quarry (Montevidiu Municipality); 2. Stereosternum tumidum isolated haemal arch (the scale is two centimeters long). Boa Vista Quarry (Montevidiu Municipality); 3. Remains of Stereosternum tumidum. See isolated haemal archs. Perolândia District (Jataí Municipality); 4. Nodules with Stereosternum tumidum bony fragments. Boa Vista Quarry (Montevidiu Municipality); 5. A young specimen of Stereosternum tumidum presenting cervical rotation and skull dislodgement. Perolândia District (Jataí Municipality)

favoráveis para observações e contagem; outros espécimes não representados fotograficamente também não apresentam cauda completa.

As vértebras são quadráticas em vista dorsal, retas lateralmente e onduladas nas faces anterior e posterior. Há diminui- ção de tamanho para trás, sendo que a primeira é mais achatada do que as seguintes, confirmando os aspectos descritos por Cope (1886); têm espinha neural proeminente, voltada para trás, aguda e mais característica na parte mediana da cauda. Mostram dois canais preservados e parcialmente preenchidos 


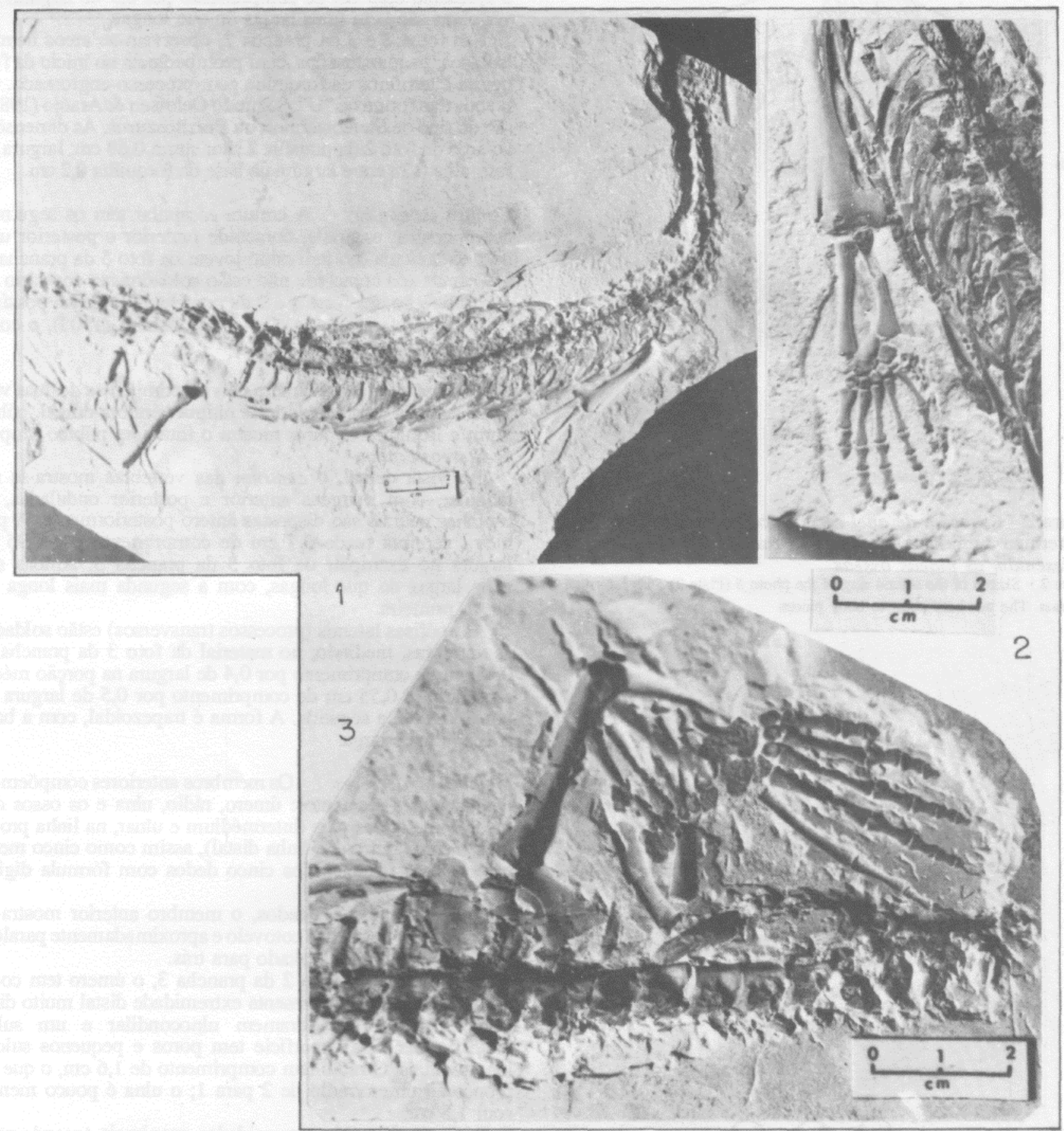

Prancha 3-1. Esqueleto de Stereosternum tumidum com pálato, região cervical, cintura escápular, membro anterior direito (molde), região tóraco-lombar, cintura pélvica, membros posteriores, parte da cauda e plástron de costelas abdominais. Distrito de Perolândia (Municipio de Jatai); 2. Contramolde do membro anterior direito mostrado na Foto 1; 3. Detalhes dos membros posteriores mostrados na Foto 1 (a perna esquerda está sob a direita)

Plate 3-1. Stereosternum tumidum skeleton showing palate, cervical region, shoulder-girdle, right fore limb (mold), thoraco-lumbar region, pelvic-girdle, hind limbs, part of the tail and abdominal ribs. Perolândia District (Jataí Municipality); 2. Cast of the Photo 1 right fore limb; 3. Details of the Photo 1 hind limbs (the left leg is under the right one)

por material secundário, um sob o outro; no de baixo, há estreitamento na parte mediana de algumas vértebras, sugerindo não-continuidade e talvez preenchimento, em vida, por cartilagem.

As costelas caudais são proeminentes nas primeiras vertebras (as dez vértebras caudais do espécime da foto 1 da prancha 3 possuem costelas), diminuindo para o fim da cauda.
Os arcos hemais aparecem a partir da quarta vertebra caudal e é desconhecido seu término.

Uma vista posterior de vertebra caudal (Foto 4, Prancha 1), que segundo Oelofsen (1981) seria de posição mediana, mostra centrum em forma de sino, com boca para cima e apófise neural (ou dorsal) em forma de sino com boca para baixo, com cintura entre essas duas partes. Estão presentes: 

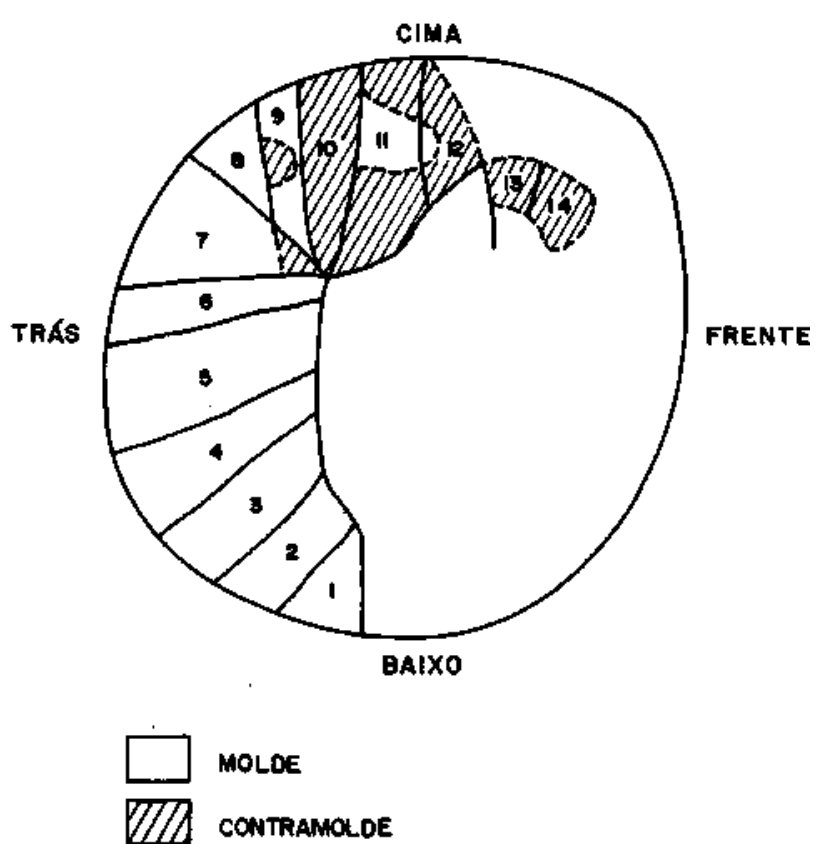

Figura 2 - Esquema de anel esclerótico do espécime de Stereosternum tumidum da foto 5 (Prancha 2). Os números representam as placas ósseas

Figure 2 - Sketch of the scleral ring of the photo 5 (Plate 2) Stereosternum tumidum. The numbers point to bony pieces

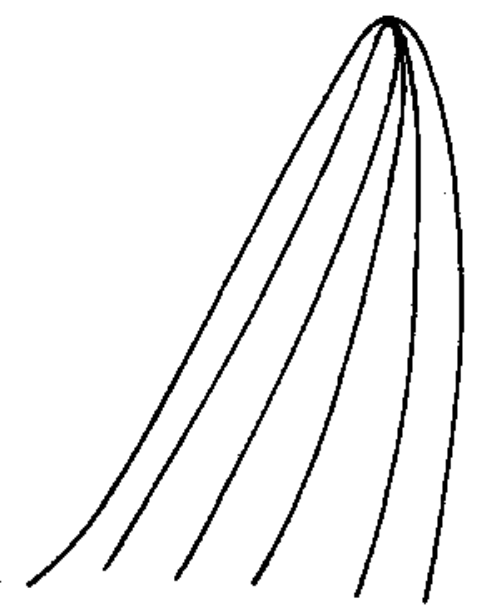

EM CORTE

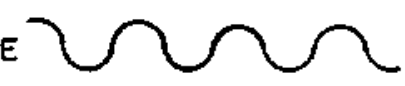

Figura 3 - Esquema de estriação no esmalte de dente de espécime de Stereosternum tumidum da foto 1 (Prancha 2) Figure 3 - Sketch of the striation of the enamel of a tooth from photo 1 (Plate 2) Stereosternum tumidum

espinha neural proeminente (processo dorsal), zigosfeno, canal medular, costela caudal (processo transverso), intercentro e arco hemal. As suas dimensões são as seguintes: altura 1,03 $\mathrm{cm}$, largura $0,53 \mathrm{~cm}$, diâmetro do canal medular $0,1 \mathrm{~cm}$, altura do arco hemal $1,08 \mathrm{~cm}$, largura da forquilha do arco hemal $0,35 \mathrm{~cm}$, comprimento da costela caudal $0,88 \mathrm{~cm}$ e altura do processo dorsal $0,3 \mathrm{~cm}$.
A primeira vertebra caudal do animal da foto 1 da prancha 3 apresenta $0,65 \mathrm{~cm}$ de comprimento por 0,9 de largura. As vértebras são bem mais largas do que longas.

Nas fotos 2 e 3 da prancha 2, observam-se arcos hemais isolados, paquiostosados, com protuberância no início da forquilha e términos da forquilha com processo engrossado. Os braços têm forma de "U". Segundo Oelofsen \& Araújo (1983), são do tipo de Stereosternum ou Brazilosaurus. As dimensões do arco da foto 2 da prancha 2 são: altura $0,68 \mathrm{~cm}$, largura da forquilha $0,28 \mathrm{~cm}$ e largura na base da forquilha $0,2 \mathrm{~cm}$.

Cintura escápular A cintura escápular tem os seguintes componentes: escápula, coracóide (anterior e posterior unidos) e clavícula (no indivíduo jovem da foto 5 da prancha 2 , a escápula e o coracóide não estão soldados, ao contrário do que ocorre no das fotos 1 e 2 da prancha 3 ). Não foi possível observar a interclavícula. Como em Osborn (1903), o coracóide apresenta um foramem.

Cintura pélvica A cintura pélvica compõe-se de duas vertebras sacrais bem acopladas à última vertebra dorsal, púbis, flium e ísquium. O púbis mostra o foramem púbico próprio de Stereosternum.

Em vista dorsal, o centrum das vértebras mostra-se retangular, com margens anterior e posterior onduladas, as espinhas neurais são dispostas ântero-posteriormente. A primeira vertebra mede $0,7 \mathrm{~cm}$ de comprimento por $0,95 \mathrm{de}$ largura no exemplar da foto 3 da prancha 3 . Ambas são mais largas do que longas, com a segunda mais longa do que a primeira.

As apófises laterais (processos transversos) estão soldadas às vértebras, medindo, no material da foto 3 da prancha 3 , $0,45 \mathrm{~cm}$ de comprimento por 0,4 de largura na porção média a primeira e $0,55 \mathrm{~cm}$ de comprimento por 0,5 de largura na porção média a segunda. A forma é trapezoidal, com a base afastada mais larga.

Membros anteriores Os membros anteriores compõem-se dos seguintes elementos: úmero, rádio, ulna e os ossos das mãos com sete carpais (intermedium e ulnar, na linha proximal, e cinco outros na linha distai), assim como cinco metacarpos, e as falanges dos cinco dedos com fórmula digital 2-3-4-4-3.

Nos espécimes estudados, o membro anterior mostra-se retihneo, sem ângulo no cotovelo e aproximadamente paralelo ao tronco do animal, voltado para trás.

No exemplar da foto 2 da prancha 3 , o úmero tem comprimento de $32 \mathrm{~cm}$, apresenta extremidade distai muito dilatada e mostra um foramem ulnocondilar e um sulco radiocondilar. Sua superfície tem poros e pequenos sulcos longitudinais. O rádio tem comprimento de $1,6 \mathrm{~cm}$, o que dá proporção úmero/rádio de 2 para 1; o ulna é pouco menor, com $1,5 \mathrm{~cm}$.

Rádio e ulna têm extremidades proximais tocando-se e extremidades distais afastadas em quatro milímetros no exemplar acima citado. Entre as extremidades distais de rádio e ukia há o intermedium; o ulnar fica próximo ao fim do ulna. $\mathrm{O}$ intermedium é maior que os demais ossos carpianos.

Além do intermedium e do ulnar na linha proximal, o carpo compõe-se de mais cinco ossos menores na Unha distai nãocoossifiçados, sendo o quarto o maior e o quinto o menor, com possibilidade de que este fosse em parte cartilaginoso. Cada um corresponde a um metacarpo. Entre o intermedium e o ulnar há um foramen que, segundo Mac Gregor (1908), constitui passagem para a artéria perforans mesopodii.

O primeiro metacarpo é mais curto e grosso que os demais, o segundo é o mais longo. No exemplar da foto 2 da prancha 3 , todos têm um sulco longitudinal na porção proximal. Há encurtamento do segundo para o quinto. Os metacarpos são mais longos que as falanges, as quais diminuem de compri- 
mento para o fim dos dedos. As últimas falanges têm vestígios de unhas.

Membros posteriores Os membros posteriores compõemse dos seguintes elementos: fêmur, tíbia, fíbula; os ossos dos pés, com sete tarsais (intermedium e fibular na linha proximal e cinco outros na linha distai), assim como cinco metatarsos; as falanges dos cinco artelhos têm fórmula digital 2-3-4-5-5 ou 2-3-4-5-6. A possibilidade de haver seis ossos ao invés de cinco no quinto dedo deve-se ao fato de que o indivíduo da foto 3 da prancha 3 , o único com pés em boas condições para contagem, mostra cinco ossos no quinto dedo do pé direito, podendo a última falange mostrada não ser realmente a última, em virtude da perda, na preparação, de pequena porção de amostra que continha o final desse dedo, enquanto em razão de a perna esquerda estar fossilizada por baixo da direita, o fêmur desta apoiou-se sobre o quinto dedo do pé esquerdo, de modo a poder existir outra falange além das cinco mostradas.

$\mathrm{O}$ membro posterior direito mostra o fêmur em ângulo quase reto com o tronco, com pequena inclinação para trás e joelho em ângulo reto com o fêmur, também para trás.

No exemplar da foto 3 da prancha 3 , o fêmur tem comprimento de $3,4 \mathrm{~cm}$, apresentando ligeira forma de "S". Não há cabeça bem distinta (trocânter) na extremidade proximal, que termina de forma achatada e possui concavidade lateral. A extremidade distai tem superfície convexa lisa, formando pequena cunha (bisel) e mostrando compressão lateral (concavidade). Há pequenas estrias longitudinais na superfície do fêmur.

A tíbia é grossa na parte proximal e fina na distai (forma de taco de bilhar), onde possui truncação que forma ângulo agudo com o intermedium.

O comprimento da tíbia é de $2 \mathrm{~cm}$, o que dá relação aproximada de comprimento fêmur/tíbia de 7 para 4 , relação essa típica de Stereosternum, conforme Mac Gregor (1908).

A fíbula tem largura homogênea, curvando-se para fora e seu comprimento na amostra da foto 3 da prancha 3 é de $2 \mathrm{~cm}$.

Tíbia e fíbula estão próximas na parte proximal e afastadas cerca de cinco milímetros na parte distai (Foto 3, Prancha 3), com o intermedium entre elas.

O tarso compõe-se dos elementos intermedium e fibular na linha proximal e mais cinco ossos na Unha distai. O intermedium e o fibular não estão soldados e existe uma passagem (foramem) provavelmente para artéria. O fibular apresenta elongação conspícua dos espécimes adultos de Mesosaurus tenuidens, no dizer de Oelofsen (1981).

Os ossos tarsais distais não são coossificados, sendo o quarto o maior deles e o quinto o menor, podendo ser possível que o quinto elemento fosse em parte cartilaginoso (parece todavia, tratar-se de tarso totalmente ossificado).

O primeiro metatarso é mais curto e grosso que os demais, havendo aumento de tamanho para o quinto. Os metatarsos são mais longos que as falanges.

O quinto dedo tem mais do que o dobro do comprimento do primeiro. Conforme Mac Gregor (1908), no material em estudo, o quinto artelho está curvado para fora da mão e sua distância (espaço) para o quarto é maior do que entre os demais. Mac Gregor (1908) inverte a ordem dos dedos, chamando de quinto ao primeiro e vice-versa.

As falanges diminuem de comprimento para o fim dos dedos, havendo vestígios de unhas nas últimas.

$\mathrm{O}$ pé é bem maior que a mão, possuindo mais que o dobro da área dela.

Fragmentos ósseos A foto 4 da prancha 2 é de um dolomito claro, possuindo leitos com cerca de dois centímetros de espessura, parcialmente silicificados, apresentando nódulos com aspecto de elipsóide bem achatado, de cor marrom, de dimensões aproximadas de $1,5 \mathrm{~cm}$ de comprimento por 0,5 de largura e 0,1 de altura, compostos por fragmentos ósseos com grãos de quartzo do tamanho silte. A margem é lisa e não há direção preferencial dos nódulos na amostra.

A quantidade de nódulos é de cerca de 12 para cada 100 $\mathrm{cm}^{2}$ de superfície de rocha. De modo geral, os fragmentos não podem ser identificados, mas trata-se de ossos dos próprios répteis, o que se constata pelos poucos identificáveis. Há o mesmo material em Jataí (Perolândia) e Montevidiu. Os nódulos misturam-se a fragmentos ósseos menores que eles, de vários tamanhos, isolados ou não. Conseqüentemente, esses aglomerados formaram-se por meio de processo seletivo ligado à diferença de densidade dos ossos com relação ao material detrítico mineral no corpo aquoso, associada ao pequeno movimento das águas, portanto sem transporte.

Tamanho e juventude É feita aqui uma pequena discussão sobre o tamanho dos indivíduos. Muitos elementos de esqueletos, principalmente vértebras e costelas, têm tamanho maior do que os correspondentes dos espécimes descritos e fotografados.

O comprimento da parte fossilizada do animal da foto 1 da prancha 3 é de $34 \mathrm{~cm}$; admitindo-se o comprimento do crânio como sendo igual ao do pescoço $(6,7 \mathrm{~cm})$, sendo de $16 \mathrm{~cm}$ a distância entre as cinturas escapuíar e pélvica; admitindo-se como sendo de 60 a 64 o número total de vértebras caudais, conforme Osbom (1903) e visto que as dez vértebras caudais espécime têm $6,5 \mathrm{~cm}$ de comprimento, chega-se a comprimento total aproximado de $68 \mathrm{~cm}$.

É provável, portanto, que a espécie tivesse comprimento maior, em virtude da existência de fragmentos de esqueletos maiores do que as porções correspondentes do esqueleto da foto 1 da prancha 3 .

Sobre o esqueleto da foto 5 da prancha 2, algumas considerações precisam ser feitas:

1.0 crânio possui focinho curto, cavidade orbital grande (um espécime não fotografado tem cavidade orbital proporcionalmente menor) e dentes muito cônicos (especialmente os medianos e traseiros nas arcadas dentárias). 2.0 tamanho do crânio é pequeno em relação ao comprimento do pescoço $(2,8$ para $4,3 \mathrm{~cm})$.

3. A escápula e o coracóide não estão soldados, estando, ao contrário, distantes.

4. O esqueleto é de tamanho pequeno.

As características acima apontadas sugerem tratar-se de indivíduo jovem e não de espécie diferente ou de dimorfismo sexual, já que:

1. O número de vértebras cervicais é igual ao de outros espécimes (doze vértebras).

2. Escápula e coracóide não-coossifiçados sugerem existência de cartilagem ligando os mesmos, o que seria próprio de indivíduo jovem.

3. O pequeno tamanho do esqueleto, embora possa sugerir também dimorfismo sexual, é muito mais sugestivo de fase de crescimento.

4. Sobre a forma e o tamanho do crânio e ainda a forma e o tamanho dos dentes, esses aspectos falam com igual potencial para diferença específica, dimorfismo sexual e fase de crescimento.

Shikama \& Ozaki (1966) não aceitam as características dos dentes iguais às do exemplar aqui em análise como sendo devidas a fases de crescimento ou dimorfismo sexual em Mesosaurus ou Stereosternum, optando pelo novo gênero Brazilosaurus. Considerando, entretanto, que o número de vertebras cervicais sugere tratar-se da mesma espécie que a dos demais espécimes; que dificilmente seriam encontradas diferentes espécies no mesmo nicho ecológico; cjue as anteriores características sugerem tratar-se de indivíduo jovem; e não havendo ainda na literatura seguras evidências sobre dimorfismo sexual, é, neste trabalho, favorecida a hipótese da juventude. 
Com o exposto, é forçoso concluir que o crescimento determinaria alterações na forma craniana, promovendo alongamento do focinho (já que os outros espécimes têm focinho mais longo), diminuição relativa do tamanho da cavidade orbital em relação ao resto do crânio (haveria crescimento craniano sem crescimento correspondente da cavidade orbital) e aumento no comprimento dos dentes, embora mantendo a forma reta e cônica, conforme mostrado pelo crânio da foto 1 da prancha 2. Portanto, com o crescimento do animal, o crânio adquiriria comprimento igual ao do pescoço.

Existiria também progressão do crescimento ósseo em detrimento de ligações cartilaginosas do esqueleto.

Caracterização genérico-específica A presença de trinta e quatro vértebras pré-sacrais, mais a existência de um foramem público e dentes cônicos, curtos e retos, assim como de mandíbula reta, descartam a possibilidade de tratar-se de Mesosaurus; a existência de doze vértebras cervicais e vinte e duas tóraco-lombares elimina a possibilidade de tratar-se de Brazilosaurus sampauloensis e caracteriza o animal como Stereosternum tumidutn Cope 1886. As costelas também mais robustas do que as de B. sampauloensis falam a favor de $S$. tumidum (Shikama \& Ozaki 1966).

\section{Crustácea - Malacostraca - Pygocephalomorpha}

LIOCARIS HUENEIBEURLEN 1931 O gênero Liocaris foi proposto por Beurlen (1931), ao estudar a fauna de crustáceos da Formação Irati, em material procedente do Distrito de Assistência no Município de Rio Claro, São Paulo, coletado por Von Huene, apontando algumas características comuns com o gênero Paulocaris Clarke (1920). Nessa ocasião, embora tivesse dificuldade para efetuar separação específica, identificou duas formas, Liocaris huenei e L. angusta. É provável que essas duas espécies constituam uma única, pois "a diferença entre elas parece ser produto de fossilização" (Pinto 1971, p. 388).

Beurlen (1953) descreveu, ainda, duas novas espécies de Paulocaris, P. clarkei e P. marianoi; a primeira procedente de folhelho betuminoso da estação ferroviária de Engenheiro Gutierrez, Município de Irati, Estado do Paraná, e a segunda de leitos calcários dessa mesma formação, nos municípios de Dom Pedrito e Bagé, Estado do Rio Grande do Sul. Os espécimes, separados especificamente pelo tamanho da carapaça, não possuem a carena mediana e nem os espinhos laterais característicos de Paulocaris pachecoi Clarke do Estado de São Paulo.

É possível que essas duas novas formas do sul do Brasil, descritas por Beurlen (1953), Paulocaris clarkei, e P. marianoi, sejam referíveis a Pygaspis e Liocaris, respectivamente (Pinto 1971).

O gênero Liocaris tem sido sinonimizado com Paulocaris (Brooks 1962, Mezzalira 1971). porém Pinto (1971), reestudando as formas de Pygaspis, Paulocaris e Liocaris, opinou pela manutenção dos três gêneros, caracterizando-os da seguinte maneira, à $\mathrm{p}^{*} 399$ :

"1. Paulocaris, crustáceo de porte médio. Possui espinhos ântero-laterais; margem anterior côncava; rostro de tamanho médio".

"2. Liocaris, crustáceo de porte pequeno. Não possui espinhos ântero-laterais; margem anterior reta e rostro longo." "3. "Pygaspis", crustáceo de porte grande. Não possui espinhos ântero-laterais; margem anterior reta e rostro triangular e curto".

A presença de valvas de lamelibrânquios fósseis na região de Jataí e Montevidiu, assinaladas por Milward (1935, p. 83), constituindo "massas que se alternam com as camadas de calcário, no qual se intercala um pouco de pederneira", não foi confirmada. Essas massas são formadas por carapaças de crustáceos Liocaris, muito fragmentadas, compondo verdadeiras camadas de dolomito exploráveis, à semelhança do que se observa no dolomito dessa mesma formação no Estado de São Paulo.

A ausência de correntes ou movimentos ondulares da água antes da fossilização, com competência suficiente para orientar esses restos (ou a interação de transporte com diferentes direções) teria sido responsável pela disposição caótica das carapaças na rocha.

As formas encontradas no dolomito da região de Perolândia apresentam a carapaça comprimida, mais larga $(1,1 \mathrm{~cm})$ do que alta $(0,9 \mathrm{~cm})$, e com rostro e margem anterior indistintos devido à má preservação, sem crista mediana, bordas laterais e bordo nucal espessados (Foto 1, Prancha 4).

As formas provenientes de Montevidiu (Pedreira Boa Vista), encontradas em dolomito mais cinzento do que o de Perolândia, ao contrário, são mais altas $(0,9 \mathrm{~cm})$ do que largas $(0,4 \mathrm{~cm})$, com rostro e margem anterior indistintos, devido à fossilização e o bordo nucal espessado. Há ausência de crista mediana (Foto 2, Prancha 4).

Pelas características acima apontadas, esses espécimes foram identificados como Liocaris huenei Beurlen 1931 (Mezzalira et al 1990).

Restos indeterminados A amostra de dolomito branco-amarelado, representada na foto 3 da prancha 4 , contém restos fósseis não conhecidos.

$\mathrm{O}$ exame articular por maceração, feito pelo prof. dr. O. Rosier, do Instituto de Geociências da USP e pelo pesquisador F.C. Fittipaldi, conforme método adotado para plantas paleozóicas, revelou não se tratar de restos celulares vegetais, mas animais. Todavia, não foi possível, até agora, a identificação do material.

\section{CONSIDERAÇÕES AMBIENTAIS E TECTÔNICAS}

Como já foi visto, existe identidade litológica entre a Formação Irati, na região estudada, e o Membro Assistência, descrito para o Estado de São Paulo por Barbosa \& Gomes (1958), assim como semelhança paleontológica. "O banco de calcário econômico ocorre 8-10 m acima do contato com o Taquaral. Ele varia de 1 a $3 \mathrm{~m}$, contém abundantes restos de Liocaris e de Stereosternum e escassos exemplares de madeira silicificada castanho-escura" (Barbosa \& Gomes 1958, p. 21).

Por meio dos conteúdos litológico e paleontologia), deduz-se que a porção norte da Bacia do Paraná estaria, ao tempo de deposição da Formação Irati, dominada por águas rasas, condição propícia à formação de carbonates de cálcio e de magnésio; intermitentemente, haveria desenvolvimento de águas mais profundas, com geração de folhelhos pretos.

A dolomita é comum em ambiente lagunar, sendo formada a partir de diagênese ou epidiagênese. A existência de dolomita no Membro Assistência do sudoeste goiano sugere, portanto, ambiente costeiro lagunar, podendo todavia ser diagenética.

Nessa porção da Bacia do Paraná, ao norte do Alinhamento de Guapiara, os ecossistemas seriam propícios à proliferação de Brazilosaurus sampauloensis e Stereosternum tumidum, ao contrário da porção central (ao sul do citado alinhamento), a qual teria águas mais profundas, formadoras de folhelhos ricos em matérias orgânica, com ambiente propício à vida de Mesosaurus brasiliensis. As evidências litopaleontológicas dessa unidade são de ambiente costeiro misto e não de mar aberto. A presença de Stereosternum e Liocaris no sudoeste goiano e exclusivamente nos dolomites, assim como a maior espessura desta litologia em contraposição aos finos pelitos, estão concordes com a proposta supra-apresentada.

As marcas onduladas de corrente de pequeno porte indicam que as águas seriam ligeiramente movimentadas, mas de baixa energia, de acordo com Oelofsen (1981, p. 143 e 144): "Low amplitude oscillation ripples and the orientation of fossils however registered an oscillatory movement of a tidal nature in the bottom waters over vast tracts of the basins". As gretas 


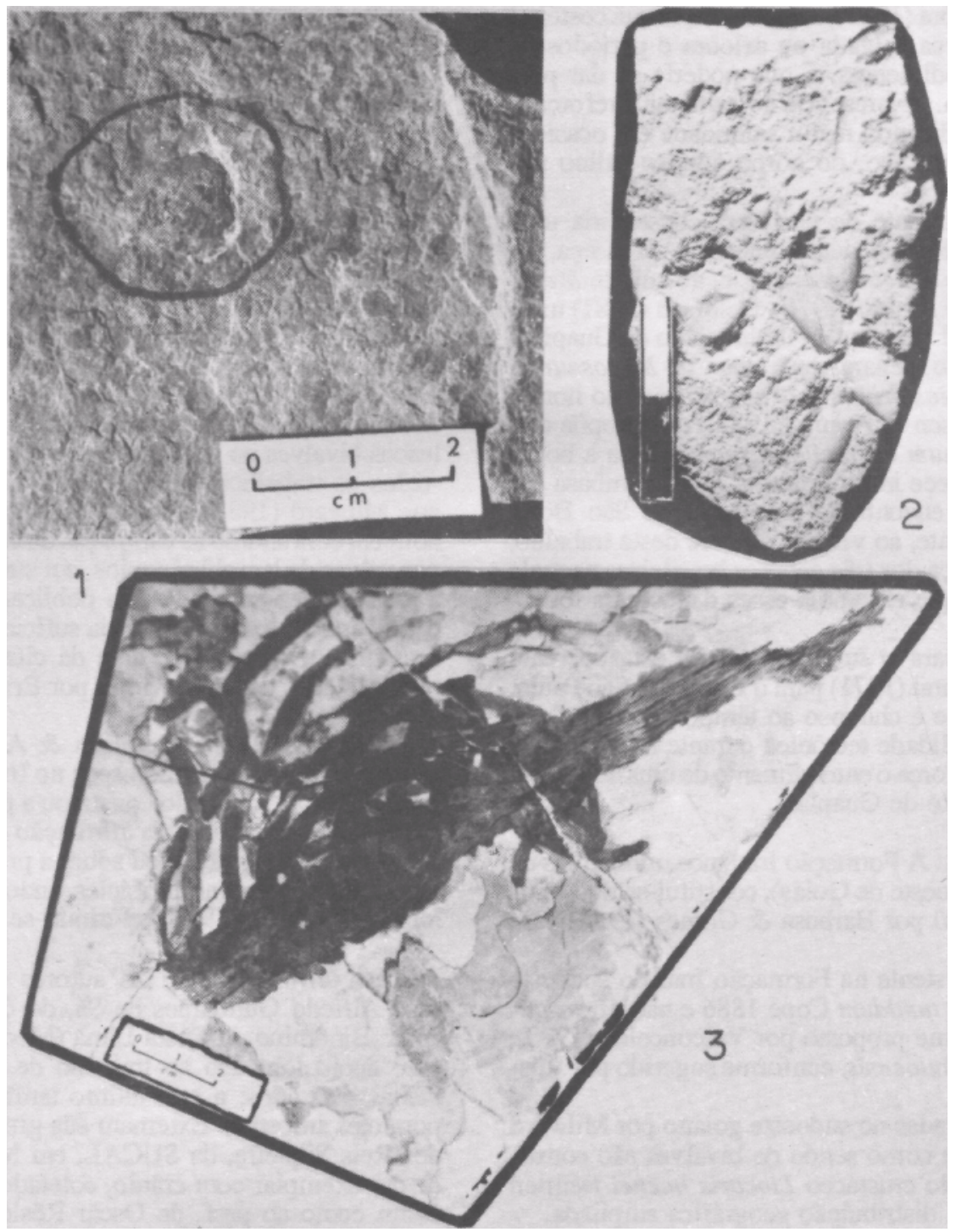

Prancha 4-1. Liocaris huenei. Distrito de Perolândia (Município de Jatai); 2. Liocaris huenei. Pedreira Boa Vista (Município de Montevidiu). (A escala tem comprimento de dois centímetros); 3. Restos fósseis animais indeterminados. Distrito de Perolândia (Município de Jataí)

Plate 4-1. Liocaris huenei. Perolândia District (Jataí Municipality); 2. Liocaris huenei. Boa Vista Quarry (Montevidiu Municipality). (The scale is two centimeters long); 3. Undetermined animal fossil remains. Perolândia District (Jataí Municipality)

de contração (Foto 3, Prancha 1) mostram a existência de períodos de rebaixamento do nível de água e exposição aérea dos sedimentos. A ausência de litoclastos e oóHtos reforça a hipótese de ambiente de baixa energia, sendo esta interpretação coerente com a exposta por Amaral (1971) para o Estado de Șão Paulo.

É também possível que as águas geradoras dos dolomites fossem mais quentes e mais agitadas do que as geradoras dos folhelhos (embora ainda de baixa energia); assim, sua agitação seria imprópria à deposição das partículas argilosas, enquanto a baixa temperatura das águas mais profundas seria imprópria à precipitação de carbonates, o que seria reforçado pelo baixo $\mathrm{pH}$ estabelecido pela riqueza de restos orgânicos.

O Membro Assistência poderia, portanto, estender-se pelo norte da bacia, desde o Estado de São Paulo até o Estado de Goiás, em direção noroeste, paralela ao Alinhamento de Guapiara (Ferreira 1982). Sua caracterização no sudoeste goiano justifica essa possibilidade.
Desta forma, o Alinhamento de Guapiara poderia prolongar-se para oeste do atual Rio Paraná, confonne as figuras de Ferreira (1982, p. 134 e 135), ou seja, para a borda oeste da bacia, delimitando, um ambiente ecológico próprio nos Estados de São Paulo, Goiás e Mato Grosso do Sul, no qual viveriam Stereosternum e Braziloaurus, não sendo propício à vida de Mesosaurus, que tinha preferência por águas mais frias, mais profundas e condições euxínicas.

E possível, entretanto, não ter havido continuidade entre o Membro Assistência de São Paulo e seu correspondente de Goiás, mas apenas a repetição provavelmente sincrônica do mesmo ambiente físico-químico e do mesmo ecossistema; todavia, essa proposta é mais difícil de ser justificada, especialmente devido à presença de Stereosternum e Liocaris, pois haveria necessidade de migração desses animais por longa distância, passando por ambientes inóspitos em uma região em parte costeira.

Como já foi dito, a presença de marcas onduladas milimétricas e gretas de contração do tipo curvo, conforme as dês- 
critas por Petri \& Coimbra (1982), sugerem ambiente costeiro, com fina lâmina de água salgada ou salobra e períodos de exposição aérea dos sedimentos, o que poderia se dar pelo recuo do corpo aquoso. A presença de esmectíta reforça o quadro apresentado, indicando maior salinidade em ocasiões de espessamento, por avanço, do corpo aquoso salino nas áreas próximas à margem.

Isto posto, o Alinhamento de Guapiara constituiria uma barreira geotectonoecológica, determinando a presença, ao norte, de Stereosternum e Brazilosaurus, e, ao sul, de Mesosaurus, como aceito por Araújo (1976). Oelofsen (1981) traça um alinhamento coincidente com o Alinhamento de Guapiara no Estado de São Paulo, separando a zona de Mesosaurus, ao sul, da zona de Stereosternum e Brazilosaurus, ao norte.

A hipótese de Oelofsen \& Araújo (1983), que propõe distribuição de Stereosternum e Brazilosaurus por toda a borda da Bacia do Paraná parece imprópria, por que se embasa em material desarticulado encontrado em Passo de São Borja (RS), que não é suficiente, ao ver dos autores deste trabalho, para assegurar a presença dos três gêneros brasileiros naquela região, e também por que extrapola esses dados para toda a borda da bacia.

Essa interpretação para o sudoeste goiano está coerente com a proposta por Amaral (1971) para o Estado de São Paulo, que sugere clima quente e chuvoso ao tempo da gênese dos dolomites, com tranqüilidade tectônica durante a geração de toda a unidade, o que reforça o entendimento de uma sub-bacia ao norte do Alinhamento de Guapiara.

CONCLUSÕES 1. A Formação Iratí, nos municípios de Jataí e Montevidiu (sudoeste de Goiás), constitui-se do Membro Assistência, descrito por Barbosa \& Gomes (1958) para o Estado de São Paulo.

2. O mesossaurídeo existente na Formação Irati do sudoeste goiano é Stereosternum tumidum Cope 1886 e não Mesosaurus brasiliensis, conforme proposto por Vasconcelos (1973), ou Brazilosaurus sampauloensis, conforme sugerido por Rosier (1985).

3. As carapaças encontradas no sudoeste goiano por Milward (1935) e tidas até agora como sendo de bivalves são constituídas, na realidade, pelo crustáceo Liocaris huenei Beurlen 1931, que fica com sua distribuição geográfica ampliada. 4.0 Alinhamento de Guapiara, introduzido na literatura geológica por Ferreira (1982), constituíu-se numa barreira geotectonoecológica ao tempo da sedimentação da Formação Irati, estabelecendo, ao norte, uma zona propícia à existência de Stereosternum e Brazilosaurus (Membro Assistência) e, ao sul, uma zona propícia à existência de Mesosaurus brasiliensis, composta principalmente por folhelhos pretos.

CONSIDERAÇÕES FINAIS 1. A presença de Stereosternum e Liocaris nos mesmos horizontes e a ausência de outros animais sugere, como afirmam Oelofsen \& Araújo
(1983), que os répteis alimentavam-se dos crustáceos, a não ser que se alimentassem de animais moles, não-fossilizáveis. 2 . Shikama (1970) propõe a existência de 12 vértebras cervicais e 23 tóraco-lombares nos espécimes tidos por ele como de Mesosaurus brasiliensis, o que é conflitante com a proposta de Mac Gregor (1908) e autores posteriores, inclusive Shikama \& Ozaki (1966), afirmando, estes últimos, à p. 357, que em Mesosaurus há 10 vértebras cervicais. Mesosaurus brasiliensis é tido como possuidor de 29 vértebras pré-sacrais, número que não coincide com o total de 35 proposta por Shikama (1970); a quantidade de 35 não coincide com os totais de vértebras nos gêneros já descritos para a América do Sul e África do Sul.

3.0 DNPM (1975) relata a presença de moluscos no Córrego da Boa Vista (Montevidiu), assim como impressões de moluscos bivalves no Córrego da Mateira (Montevidiu). Consultados os trabalhos citados na sua bibliografia, constatou-se que Milward (1935), no qual os outros autores se embasam, houvera confundido as carapaças de crustáceos-malacostracos por valvas de lamelibrânquios, em suas campanhas realizadas a mais de dez anos antes da publicação póstuma de seu trabalho, época em que não havia suficiente conhecimento sobre o assunto. O mesmo se diga da citação de pelecípodes nas proximidades de Montevidiu, por Erichsen \& Miranda (apua Mendes 1967).

4. Oelofsen (1981) e Oelofsen \& Araújo (1983) citam, em figuras, a presença de moluscos no Irati, tendo por base MezzaUra (1971), o qual não constatou a presença desses animais, apenas mencionando uma afirmação de Clarke nesse sentido. Mezzalira (1971) escreveu sobre a presença de Amaralia, um icnofóssil, na mesma litofácies onde Oelofsen (1981) e Oelofsen \& Araújo (1983) referiram-se a moluscos.

Agradecimentos Os autores agradecem ao geólogo José Alfredo Guimarães de Sá, do $6^{\mathrm{s}}$ Distrito do DNPM, e ao sr. Binômino da Costa Lima (Meco), moradores em Jataí, pelo apoio logístico ao trabalho de campo, viabilizando as visitas e estudos; a este último também pela cessão de importantes amostras. Externam sua gratidão ao sr. José Aloísio dos Reis Siqueira, da SUCAL, em Montevidiu, pela doação de um exemplar com crânio, coletado na Pedreira Boa Vista, assim como ao prof. dr. Oscar Rosier, do IGUSP e ao pesquisador Fernando Cilento Fittipaldi, pelo exame articular procedido em restos indeterminados. Agradecem ainda ao prof. Dr. Raphael Hypolito, do IGUSP, pela feitura de análise química em contramolde do réptil, e ao geólogo Jairo de Sant'Anna Taddeo, da DGRM-IPT, pela realização das difratogramas de raios $\mathrm{X}$ em rochas e contramoldes. Por fim, são gratos ao geólogos Paulo César Boggiani, do Instituto Geológico da Secretaria do Meio Ambiente do Estado de São Paulo, pela execução das fotografias e ao prof. dr. Setembrino Petri, da mesma instituição, pela revisão do texto, com críticas e sugestões.

\section{REFERÊNCIAS BIBLIOGRÁFICAS}

AMARAL, S.E. 1971. Geologia e petrologia da Formação Irati (Permiano) no Estado de São Paulo. São Paulo, USP/IAG. p. 5-81 (Boletim 2).

ARAÚJO, D.F. 1976. Taxonomia e relações dos Proganosauria da Bacia do Paraná. An. Acad. bras. Cien., 48(1):91-116.

BARBOSA, O. \& GOMES, FÃ. 1958. Pesquisa e petróleo na bacia do Rio Corumbatai, Estado de São Paulo. Rio de Janeiro, DNPM/DGM. 40 p. (Boletim 171).

BEURLEN, K. 1931. Crustacenreste aus den Mesossaurierchichten (Unterperm) von Brasilien (S.Paulo). Paleont. Zeit., 13:22-50.

BEURLEN, K. 1953. O gênero Paulocaris clarke nas camadas Irati do Brasil meridional. Rio de Janeiro, DNPM/DGM. 9 p. (Notas Prels. Ests. 65).

BORGOMANERO, G. \& LEONARDI, G. 1979. Anel esclerótico e outras peculiaridades em espécime de Stereosternum tumidum (Proganosauria Baur, 1887) de Assistência, São Paulo. In: SIM. REG. GEOL., 2. Rio Claro, 1979. Atas... Rio Claro, SBG/NSP. v.1, p. 175-179.
BROOKS, H.S. 1962. The paleozoic Eumalacostraca of North America. $N$. Y. Buli. Amer. Paleon., 44(202):335 p. (66 est).

CLARKE, J.M. 1920. Novos Crustáceos Paleozóicos. - Crustáceos do Permiano de São Paulo, Brasil. Rev. IGG., 4(1): 115-118. (Fig. 1-la, 1946).

COPE, E.D. 1886. A contribution to the vertebrate paleontology of Brazil. Proceedings of the American Philosophical Society, XXJH(121):1-21. (Held At Philadelphia, for promoting useful knowledge).

DEPARTAMENTO NACIONAL DA PRODUĈ̃O MINERAL 1975. Geologia do Brasil ao milionésimo. Folha de Goiânia (Se-22). Texto explicativo. Brasilia, DNPM. 87 p.

FERREIRA, F.J.F. 1982. Integração de dados aeromagnéticos e geológicos. configuração e evolução tectônica do Arco de Ponta Grossa. São Paulo. 169 p. (Dissertação de Mestrado, IG/USP). (2 anexos).

Mac GREGOR, J.H. 1908. On Mesosaurus brasiliensis nov. sp. from the Permian of Brazil. Relatório final da comissão de Estudos da Minas de 
Carvão de Pedra do Brasil Rio de Janeiro, Imprensa Nacional, p. 300-336. (Parte u)

MENDES, J.C. 1967. The Passa Dois Group (The Brazilian portion of the Paraná Basin). In: BIGARELLA, J.J.; BECKER, R.D.; PINTO, ID. eds. Problems in Brazilian Gondwana Geology, First Internacional Symposium of Gondwana Stratigraph Paleontogy. Curitiba, p. 119-166. MEZZALIRA, S. 1971. Contribuição ao conhecimento da geologia de subsuperfície e da paleontologia da Formação Irati no Estado de São Paulo. An, Acad. bras. Cien, 43(Supl):273-336.

MEZZALJRA, S.; VIEIRA, P.C.; FERREIRA, FJ.F. 1990. Mesosauridae e Crustacea-Malacostraca nos jazigos fossilíferos de Perolândia e Montevidiu, Estado de Goiás. Rev. Inst. Geol., 8-10-11(1):55.

MELWARD, G.B. 1935. Contribuição para a geologia do Estado de Goyaz. São Paulo, Escolas Profissionais Salesianas. 98 p.

OELOPSEN, B.W. 1981. An anatomical and systematic study of the family Mesosauridae (Reptilia: Proganosauria) with special reference to its associated fauna and palaecologia environment in the Whitehall Sea. Stellenbosch. 163 p. (Tese de Doutoramento, University of Stellenbosch).

OELOFSEN, B. \& ARAÚJO, D.C. 1983. Palaeoecological implications of the distributions of Mesosaurid reptiles in the Permian Irati Sea (Paraná Basin), South America. Rev. Bras. Geoc., 13(1): 1-6.

OSBORN, RE 1903. The reptilian subclasses Diapsida and Synapsida and the early of the Diaptosauria. Memoirs of the American Museum of Natural History, 1(8):451-507.

PETRI, S. \& COIMBRA, A.M. 1982. Estruturas sedimentares das Formações Irati e Estrada Nova (Permiano) e sua contribuição para elucidação dos seus paleoambientes geradores. In: CONGR. LATINOAMER. GEOL., 5. Buenos Aires, 1982. Atas... Buenos Aires, v.2, p. 357-371.
PINTO, I.D. 1971. Reconstituição de Pygaspis Beurlen, 1934 (Crustacea-Pygocephalomorpha). Sua posição sistemática, seu significado e de outros fósseis para o Gondwana. An. Acad. bras. Cien., 43(Supl):387-401.

RÕSLER, O. 1985. Descoberta contradiz teoria sobre a Pré-História. Jornal Folha de S. Paulo, p. 29 (Geral - Educação e Ciência, 4/7/85).

SEDOR, FÃ. \& RSLER, O. 1985. Ocorrência de formas jovens de mesossaurídeos associados a um adulto, em Jataí, Goiás (Formação Irati, Permiano Superior). In: CONGR. BRÁS. PALEONT., 9. Fortaleza, 1985. Resumo das Comunicações... Rio de Janeiro, SBP. p. 131.

SHKAMA, T. 1970. On some Mesosaurus skeletons kept in Japan. Sci. Reports of the Yokoama, (16):29-49.

SHJXAMA, T. \& OZAKI, H. 1966. On reptilian skeleton from the palaeozoic formation of San Paulo, Brazil. Trans. Proc. Soc., 64:351-358.

SUGUIO, K. 1980. Rochas Sedimentares. Propriedade - Gênese Importância econômica. São Paulo, Edgard Blücher/USP. 500 p.

TEIXEIRA, G.P. 1932. Reconhecimento geológico de Rio Verde ao Araguaya (Estado de Goyaz). Rio de Janeiro, MA-SGM. 34 p. (Boi. 59).

VASCONCELOS, J.B. 1973. Jazido fossilífero de Perolândia - Município de Jataí (Goiás). In: CONGR. BRÁS. GEOL., 27. Aracaju, 1973. Resumo das Comunicações... Aracaju, SBG/NCO. Bol. 1, p. 136-137.

MANUSCRITO A664

Recebido em 19 de junho de 1990 Revisão do autor 5 de novembro de 1990 Revisão aceita 27 de junho de 1991 